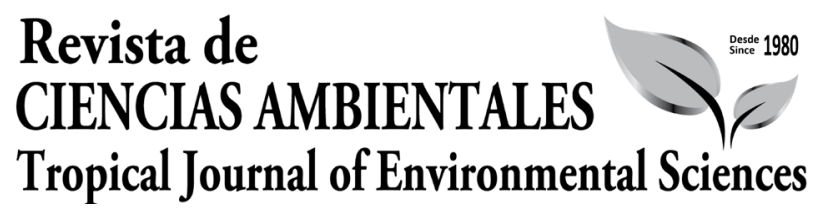

Revista de Ciencias Ambientales (Trop J Environ Sci) e-ISSN: 2215-3896

(Enero-Junio, 2021) . Vol 55(1): 317-326 DOI: https://doi.org/10.15359/rca.55-1.15

Open Access: www.revistas.una.ac.cr/ambientales e-mail: revista.ambientales@una.ac.cr

May R. H.

\title{
BIOGRAFÍA \\ Alexander F. Skutch: ornitólogo, filósofo, naturalista y conservacionista
}

\author{
Alexander F. Skutch: Ornithologist, philosopher, naturalist, and conservationist
}

Roy H. May ${ }^{1}$

\section{Introducción}

Sin duda alguna, durante casi todo el siglo XX, Alexander Frank Skutch (1904-2004) fue un naturalista de renombre mundial y un destacado ornitólogo neotropical. Recibió numerosos premios como reconocimiento por sus contribuciones a la ornitología y la literatura naturalista, entre ellos: miembro de categoría de la American Ornithologists' Union (AOU, ahora American Ornithological Society AOS) (1946); la medalla Brewster de la AOU (1950); el Premio Nacional Aquileo J. Echeverría, del Ministerio de Cultura, Juventud y Deportes por su libro Aves de Costa Rica (Skutch, 1977); el Premio Arthur Allen, del Laboratorio de Ornitología de la Universidad de Cornell (1983); presidente honorario de la Asociación Ornitológica de Costa Rica (AOCR) (1993); el Premio INBio al Mérito en la Conservación de la Biodiversidad Costarricense (2000); y el Premio Miller de la AOS/ Cooper Ornithological Society por sus contribuciones a la ornitología (Abarca, 2004).

Fue un minucioso observador de la naturaleza, quien dedi-

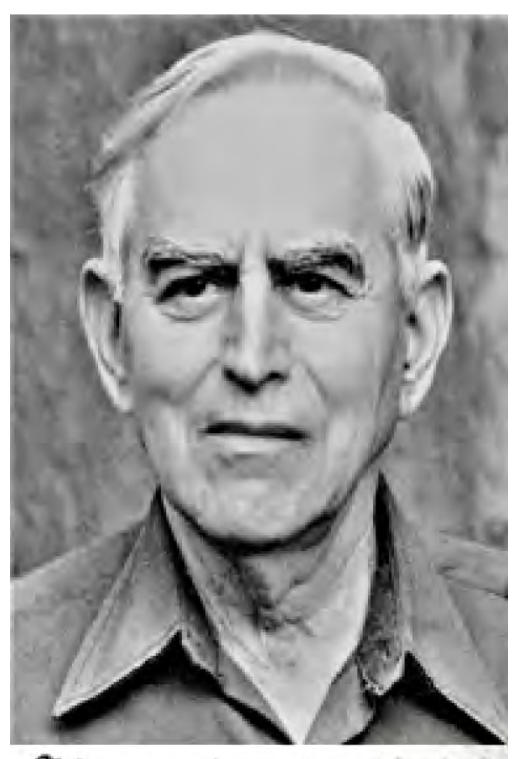
có innumerables horas a vigilar lo que ocurría en el nido de un

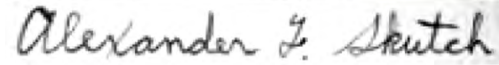
ave. Asimismo, escribió más de 40 libros y 260 artículos científicos y populares sobre las plantas y los animales silvestres, además de reflexiones filosóficas acerca del sentido de la vida y la importancia moral de las aves. Todos estos escritos Skutch los publicó en revistas conocidas.

Es pertinente indicar que casi todos sus escritos, incluyendo los inéditos, además de artículos acerca de él, están disponibles en un portal específico (http://www.alexanderskutch. com); aunque la mayoría permanece sin traducir al español. Al respecto, en español, existen una

1 Miembro de la Asociación Ornitológica de Costa Rica (AOCR) y la Northern Arizona Audubon Society. Estados Unidos de América (EE. UU.), royhmay@gmail.com

\begin{tabular}{|c|c|c|}
\hline  & (c) ${ }_{\mathrm{BY}} \mathrm{NC}_{\mathrm{NA}}$ & 317 \\
\hline
\end{tabular}




\section{Revista de CIENCIAS AMBIENTALES Tropical Journal of Environmental Sciences}

Revista de Ciencias Ambientales (Trop J Environ Sci) e-ISSN: 2215-3896

(Enero-Junio, 2021) . Vol 55(1): 317-326 DOI: https://doi.org/10.15359/rca.55-1.15

Open Access: www.revistas.una.ac.cr/ambientales e-mail: revista.ambientales@una.ac.cr

May R. H.

amplia biografía, Alexander Skutch: La voz de la naturaleza de Carlos Abarca (2004) y una extensa entrevista con Skutch en el libro Los viejos y los árboles editado por Luko Hilje et al. (2002).

También una edición especial de la revista Comunicación (2005), intitulada Alexander Skutch, en el que varios especialistas analizan sus aportes biológicos y filosóficos. Además, está disponible una breve antología de algunas de sus obras, Armonización. Aportes filosóficos para la biología y la ética ambiental editado por el autor de esta semblanza (Skutch, 2014). En fin, no cabe duda de que Skutch contribuyó mucho al conocimiento de la naturaleza y a su conservación.

\section{Su vida}

Nació en Baltimore, Maryland (EE. UU.) el 4 de mayo del 1904, del matrimonio formado por una pareja judía. Su padre era hombre de negocios especializado en anticuarios y su madre fue especialmente activa en organizaciones de mujeres judías y de beneficencia. Curiosamente, en sus escritos autobiográficos, él apenas menciona a su padre, aún menos a su madre y nunca a su hermana ni sus dos hermanos, así como raras veces amigos y amigas. Ocasionalmente se refiere a un tío y unos primos hermanos.

A pesar de que como adulto tenía mucho interés en la religión, nunca menciona su origen judío. Es decir, conocemos muy poco acerca de su vida en familia. No obstante, sabemos que el niño Alexander participó en actividades de la sinagoga y los Boy Scouts. La familia vivía inicialmente en el campo, donde Skutch pudo caminar y disfrutar la naturaleza. Lamentablemente, su padre fracasó en sus negocios y tuvo que subastar su casa, algo que lo afectó de por vida. La familia se reubicó en una cómoda casa, pero ahora en el mundo urbano.

Para el joven Alexander, esto fue un tiempo de mucha reflexión existencial; dos compromisos marcaron el resto de su vida. Como consecuencias de la quiebra económica de su padre, él decidió vivir austeramente, sin compromisos financieros, ni deudas. Además, después de leer la poesía de Percy B. Shelly y conocer algo de las religiones de la India, se convirtió en vegetariano, esto causó malestar dentro la familia, e inicialmente Alexander no pudo seguir con su plan. No obstante, un poco más tarde pudo asumir el vegetarianismo, que mantuvo de por el resto de sus años. Estas reglas - la austeridad y el vegetarianismo - fueron el cimiento sobre el cual Skutch construyó su estilo de vida.

Al entrar a la Universidad de Johns Hopkins, en Baltimore, quiso estudiar ciencias, pero no tenía los requisitos de colegio. Finalmente, mediante la intervención de un profesor, le fue permitido tomar clases de ciencia, y optó por la carrera de botánica. Sin embargo, también le interesaban las humanidades, y por cuenta propia leía ampliamente la literatura clásica y estudió a fondo las religiones de la India.

Rechazaba la religión institucional e incorporaba a sus creencias personales muchos elementos de jainismo, especialmente el principio de ahimsa o la armonía y el respeto por todas las formas de vida. Durante su tiempo libre, así como en las vacaciones, estuvo muy activo con los Boy Scouts; fue así como pudo organizar caminatas y campamentos, con lo cual acrecentó sus

\begin{tabular}{|c|c|c|c|c|}
\hline 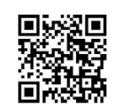 & (c) (1) (5) () & $\underset{A M B E N \text { NAILIES }}{\infty}$ & $\frac{1 \%}{2 \%}$ & 318 \\
\hline
\end{tabular}




\section{Revista de CIENCIAS AMBIENTALES Tropical Journal of Environmental Sciences}

Revista de Ciencias Ambientales (Trop J Environ Sci) e-ISSN: 2215-3896

(Enero-Junio, 2021) . Vol 55(1): 317-326 DOI: https://doi.org/10.15359/rca.55-1.15

Open Access: www.revistas.una.ac.cr/ambientales e-mail: revista.ambientales@una.ac.cr

May R. H.

propios conocimientos y el disfrute de la naturaleza, a la vez que interesó a otros jóvenes en la misma dirección.

Cuando terminó su carrera universitaria, seguía el postgrado, que culminaba en el doctorado. Se especializó en patógenos que afectan la hoja del banano. Como parte de su investigación, hizo un breve adiestramiento en Jamaica en 1926, donde colaboró con la United Fruit Company. Esta fue su primera visita al neotrópico, la cual cambió su vida, pues decidió lanzarse al neotrópico como proyecto de vida.

Fue así como al año siguiente consiguió trabajo como botánico con dicha empresa, en $\mathrm{Pa}$ namá. Hasta entonces, tenía poco interés en las aves, pero todo cambió cuando pudo observar de cerca la anidación del colibrí Amazilia tzacatl. Le fascinó tanto, que decidió dedicarse mayormente a la ornitología, aunque nunca dejó la botánica, pues ganaba su vida mediante la recolección de plantas para herbarios y museos de historia natural.

Después de una pasantía en Estados Unidos y Europa, en 1930 volvió a América Central, esta vez a Honduras, como investigador de la United Fruit Company. Allá experimentó el continuo contacto con el denso bosque lluvioso, con sus centenares de plantas, aves y otros animales. Luego de un breve tiempo en Estados Unidos, en 1933 pudo visitar a Guatemala y observar zonas de vida diferentes, desde áreas áridas hasta las montañas verdes.

Tuvo que regresar a Estados Unidos vía Costa Rica, pero se encontró con dificultades económicas. Al llegar a Puerto Limón, no tenía dinero para el pasaje. Un encuentro afortunado con el director del arboreto de la Universidad de Harvard le proporcionó tanto el pasaje como un contrato para volver a América Central como recolector de plantas.

Regresó a Guatemala - y luego, brevemente a Panamá- durante 1935. Quiso instalarse en Guatemala, pero conflictos con burócratas del gobierno le amargaron y decidió irse a Costa Rica. Encontró una casa en Rivas, en el Valle de El General, pero deseaba investigar al quetzal (Pharomachros mocinno). Esta investigación la realizó en Vara Blanca, cerca del Volcán Poás, entre 1937 y 1938. Sus investigaciones fueron los primeros estudios de la historia natural de esta emblemática ave.

Mientras tanto, trabajó brevemente, para el Museo Nacional de Costa Rica y luego tomó un trabajo con el gobierno de Estados Unidos como investigador de recursos forestales, específicamente, el hule (Hevea brasiliensis), en Sudamérica. En 1941, pudo volver a Costa Rica, compró una finca en Quizarrá de Pérez Zeledón, a orillas del río Peñas Blancas (Skutch, 1992).

Durante los siguientes 60 años, junto con su esposa Pamela Lankester Hawker - hija del cafetalero y naturalista inglés Charles H. Lankester y de Dorothea Hawker-, 16 años menor que él, con quien contrajo matrimonio en 1950, pudo estudiar la naturaleza y madurar sus pensamientos filosóficos.

No tuvieron hijos propios, pero años después la pareja adoptó a un joven, hijo de un lugareño. La familia vivía en una casa de bajareque que Skutch construyó, y para las aves sembraron un huerto con árboles frutales y ornamentales, además con muchas flores. Bautizó la finca como Los Cusingos, nombre local del tucancillo piquianaranjado (Pteroglossus frantzii), practicó

\begin{tabular}{|c|c|c|c|c|}
\hline 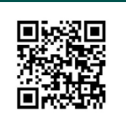 & (c) (i) (5) () & $\underset{\text { AMBIENTALES }}{\longrightarrow}$ & $\frac{10 \%}{\text { euna }}$ & 319 \\
\hline
\end{tabular}




\section{Revista de CIENCIAS AMBIENTALES Tropical Journal of Environmental Sciences}

Revista de Ciencias Ambientales (Trop J Environ Sci) e-ISSN: 2215-3896 (Enero-Junio, 2021) . Vol 55(1): 317-326 DOI: https://doi.org/10.15359/rca.55-1.15

Open Access: www.revistas.una.ac.cr/ambientales e-mail: revista.ambientales@una.ac.cr

May R. H.

métodos agroecológicos de producción y convirtió su predio en un modelo de armonía ecológica (Figura 1). Pero mantener la finca y disponer de tiempo para sus excusiones diarias al bosque demandaba mucho trabajo y tiempo, por lo que la pareja siempre tuvo ayudantes domésticos y agrícolas.

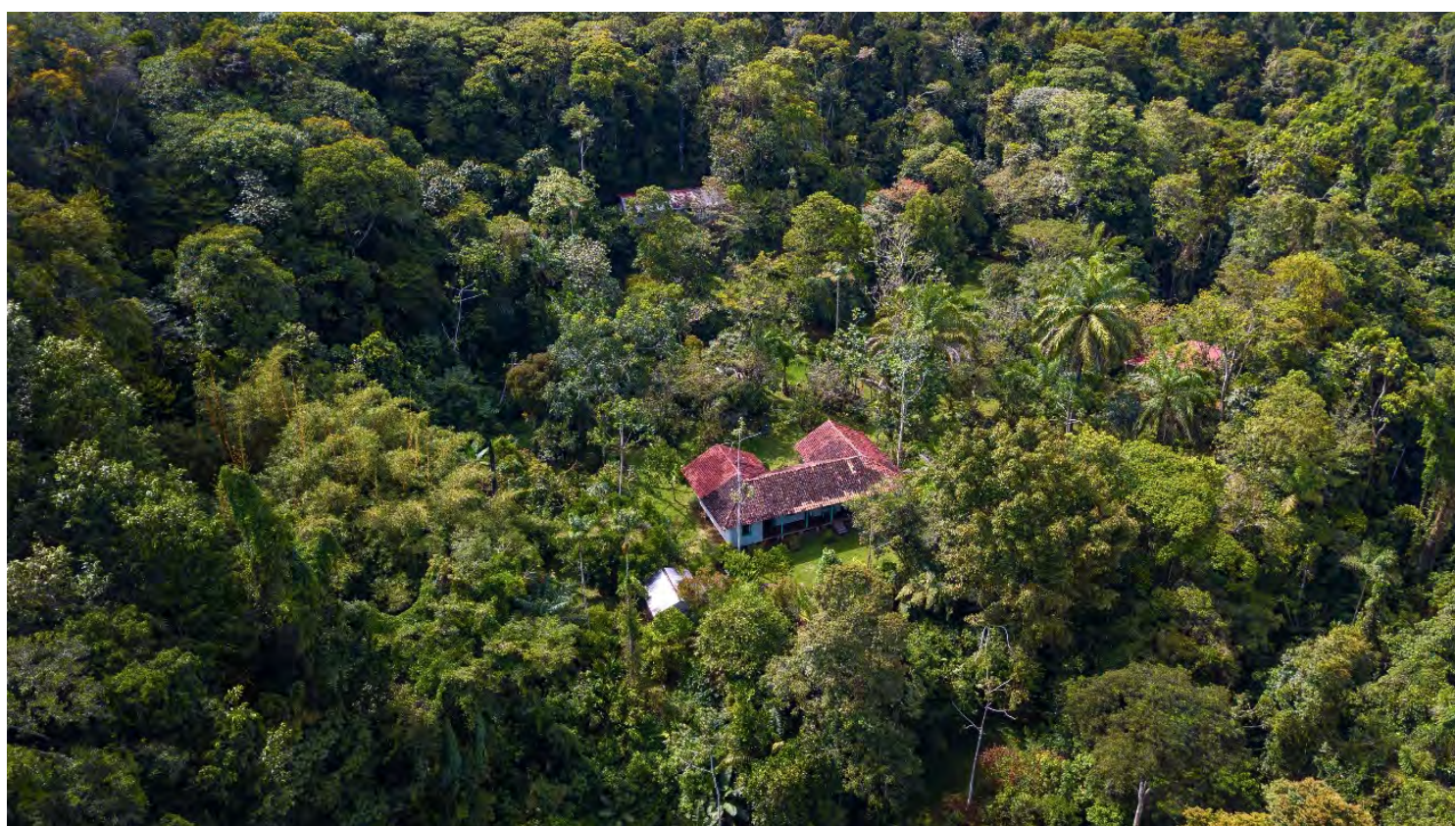

Figura 1. Entorno inmediato de la casa de Skutch. A la izquierda se observa el techo del pequeño estudio donde él solía pensar, leer y escribir.

Figure 1. Immediate surroundings of Skutch's house. On the left you can see the roof of the small study where he used to think, read, and write.

La vida en Los Cusingos fue muy austera. Skutch insistía a ultranza en la frugalidad, e incluso vivieron sin electricidad, ni agua entubada hasta el mediados del decenio de 1990. Nunca tuvieron automóvil. Fue el estilo de vida de él, pero muy difícil para su esposa, que sufría la soledad, así como la privación material y emocional.

En cierta manera, Alexander se concentró en sí mismo, en su propia ética personal, que no dejaba mucho espacio para otras personas. Fue difícil para él entablar relaciones sociales con los lugareños y no tenía buena opinión de los campesinos pobres, porque temía que dañaran el medio ambiente y porque, en su opinión, procreaban demasiados hijos. A veces sus vecinos campesinos le causaron molestias.

Más bien, se sentía cómodo con sus pares intelectuales, como los colegas del Centro Científico Tropical (CCT). No obstante, sí pudo mostrar cariño para Pamela y, de vez en cuando, colaborar con la comunidad local en diversas actividades. Por ejemplo, a veces dio charlas sobre

\begin{tabular}{|c|c|c|c|c|c|}
\hline 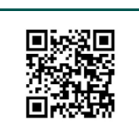 & (c) (i) () (2) (2) & $\Leftrightarrow$ & $\frac{O Q O H}{\text { eq }}$ & 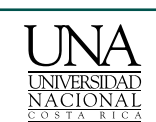 & 320 \\
\hline
\end{tabular}




\section{Revista de CIENCIAS AMBIENTALES Tropical Journal of Environmental Sciences}

Revista de Ciencias Ambientales (Trop J Environ Sci) e-ISSN: 2215-3896

(Enero-Junio, 2021) . Vol 55(1): 317-326 DOI: https://doi.org/10.15359/rca.55-1.15

Open Access: www.revistas.una.ac.cr/ambientales e-mail: revista.ambientales@una.ac.cr

May R. H.

las aves en la escuela y con frecuencia recibía escolares locales y otros visitantes, especialmente extranjeros y observadores de aves, que deseaban conocer en entorno de su finca.

En Los Cusingos permaneció hasta su muerte, ocurrida el 12 de mayo del 2004, una semana antes de cumplir cien años. Su esposa había fallecido el 29 de junio de 2001. Los restos de ambos - puesto que los de ella fueron transferidos ahí en 2006 - reposan al lado del estudio donde Skutch solía trabajar.

\section{Sus aportes intelectuales}

Botánico de formación original, sus múltiples escritos y otros aportes confirman que Skutch además fue un destacado ornitólogo, filósofo y naturalista. Por ejemplo, como recolector de plantas para museos y jardines botánicos europeos y norteamericanos, descubrió cerca de 50 especies nuevas para la ciencia. Además, sus escritos divulgativos sobre la naturaleza lo distinguieron como un promotor importante de la conservación del medio ambiente, pero con una visión muy original, como se verá después.

Ningún ornitólogo ha aportado observaciones tan meticulosas acerca de la anidación y el comportamiento de las aves, como lo hizo él. Asimismo, pocos científicos le igualan como filósofo, al ponderar profundamente el sentido de la vida. Es decir, sus aportes son numerosos y múltiples. Autodisciplinado, metódico, con gran capacidad de trabajar, salía al bosque temprano por la mañana, y cargaba una tienda, para usarla como escondite. Durante varias horas de observación de la actividad de las aves, garabateaba en una libreta sus apuntes, muy detallados. Al regresar a su casa los transcribía, ya en buena prosa y en cuadernos, intitulados Notas de campo.

En cuanto a sus reflexiones filosóficas, también las escribió en buena prosa, en cuadernos intitulados Pensamientos. Además, Skutch fue fotógrafo de la naturaleza, especialmente de las aves. Estos juegos de cuadernos y las fotos los utilizaba él como base de sus abundantes escritos. Cabe acotar que los cuadernos, otros documentos, los manuscritos y las fotos están en manos del CCT, aunque todavía no están organizados ni catalogados.

En el campo de las aves, los tres volúmenes de historias de vida de las aves centroamericanas (Skutch, 1954, 1960, 1969), se consideran como clásicos de la ornitología neotropical. A estos hay que sumar el trabajo conjunto con F. Gary Stiles, Guía de aves de Costa Rica (Stiles y Skutch, 1995), que no solo es una guía de campo, sino una verdadera enciclopedia de la historia natural de las aves que habitan este país.

Dicha obra marcó un hito histórico en la ornitología nacional y, en varios sentidos, abrió el campo a la observación de aves como un pasatiempo, lo cual a su vez ha fomentado el ecoturismo basado en la observación de aves, lo cual representa una cuantiosa fuente de divisas para dicho país. Previamente, Skutch había escrito Aves de Costa Rica (Skutch, 2014), destinado al público nacional, para presentarle una muestra de la rica avifauna del país. Su bibliografía sobre especies, familias y comportamiento de las aves es extensa.

Ente sus aportes ornitológicos, se menciona especialmente los estudios que explican las diferencias de tamaño de las nidadas entre las aves neotropicales y las de Norteamérica, así como

\begin{tabular}{|c|c|c|c|c|c|}
\hline 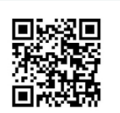 & (c) (1) (9) &  & $\frac{O \%}{2)}$ & 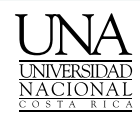 & 321 \\
\hline
\end{tabular}




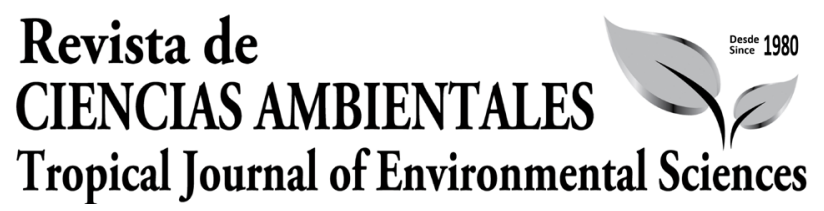

Revista de Ciencias Ambientales (Trop J Environ Sci) e-ISSN: 2215-3896 (Enero-Junio, 2021) . Vol 55(1): 317-326 DOI: https://doi.org/10.15359/rca.55-1.15 Open Access: www.revistas.una.ac.cr/ambientales e-mail: revista.ambientales@una.ac.cr

May R. H.

el comportamiento cooperativo de algunas especies de aves neotropicales. En referencia a las diferencias de tamaño de las nidadas, él indicó la alta depredación y la leve diferencia entre las estaciones en el neotrópico húmedo, en contraste con Norteamérica.

En cuanto a la anidación cooperativa, encontró más de 20 especies que siguen este patrón, como la monja frentiblanca (Monasa morphoeus) y los tijos (Crotophaga sulcirostris), que se ayudan mutuamente en la anidación y el cuidado de los pichones. Skutch creía que tal ayuda no era necesaria, por lo que concluyó que ocurrió de manera voluntaria y que demostraba los lazos fuertes entre una familia, algo que le agradó desde un punto de vista filosófico. Además, estudió la dispersión de semillas por las aves y como esta contribuye al mantenimiento y la renovación del bosque. A su vez, él destaca la importancia de la conservación de las aves, pues de ellas depende en buena parte la salud forestal y la biodiversidad de una zona.

Como naturalista, además de las aves y las plantas, estudió ampliamente los animales silvestres y sus hábitats, y plasmó sus observaciones en artículos y libros. De interés especial para Costa Rica son: Un naturalista en Costa Rica (Skutch, 2001) y La finca de un naturalista (Skutch, 2017) (Figura 2). El primero recoge muchos de sus recorridos por el país y sus observaciones respecto a la naturaleza. En el otro reflexiona sobre los animales, la geografía y la ecología de su finca Los Cusingos. Ambos aportan información importante acerca de la naturaleza de Costa Rica, así como también, una perspectiva sobre su vida cotidiana como naturalista.

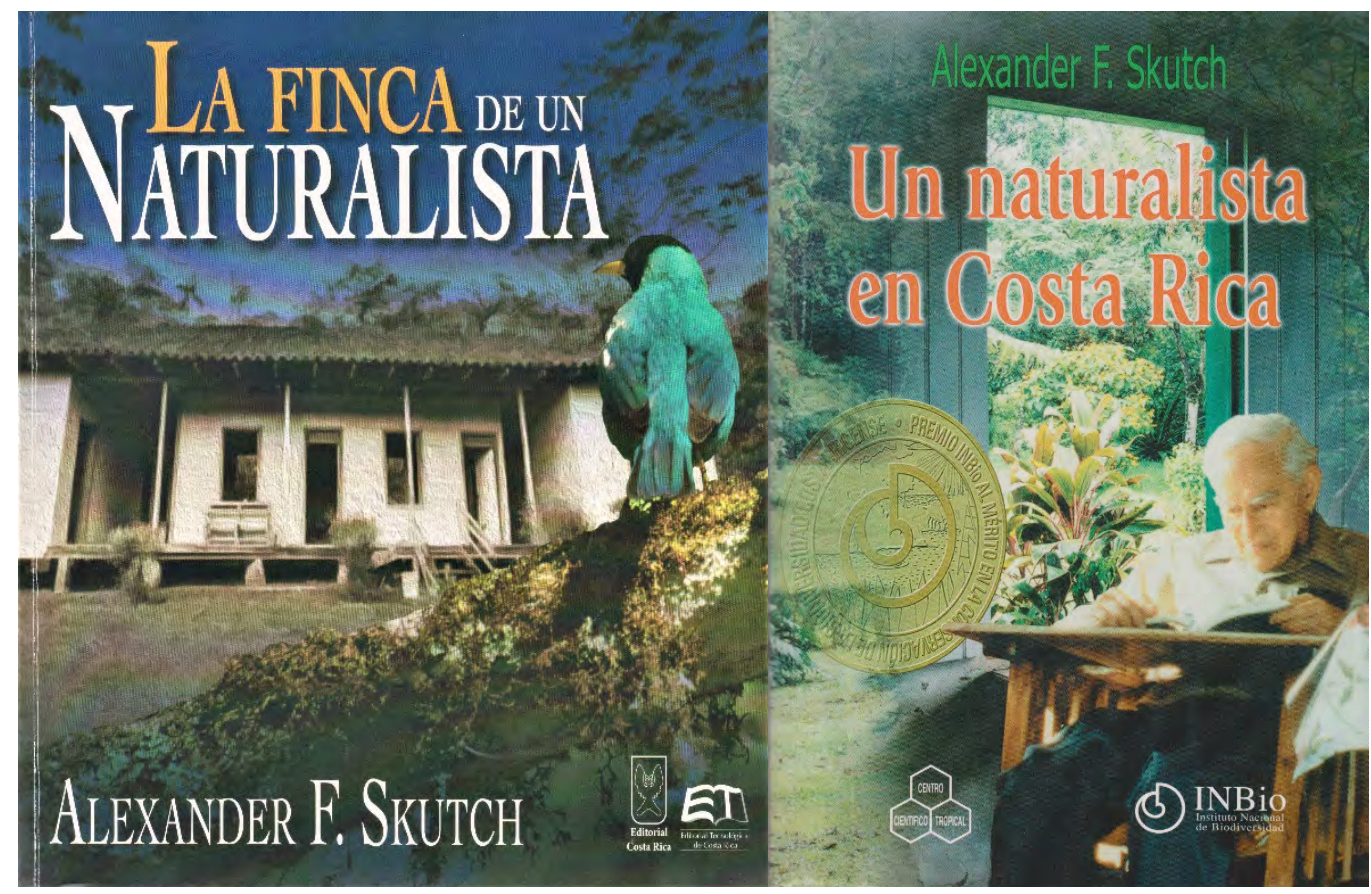

Figura 2. Carátulas de los libros mencionados.

Figure 2. Covers of the mentioned books.

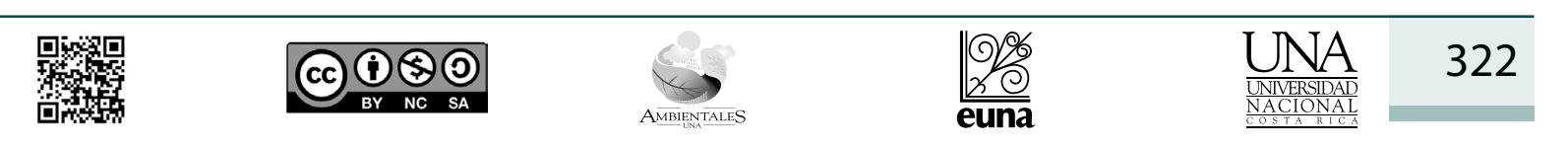




\section{Revista de CIENCIAS AMBIENTALES Tropical Journal of Environmental Sciences}

Revista de Ciencias Ambientales (Trop J Environ Sci) e-ISSN: 2215-3896 (Enero-Junio, 2021) . Vol 55(1): 317-326 DOI: https://doi.org/10.15359/rca.55-1.15

Open Access: www.revistas.una.ac.cr/ambientales e-mail: revista.ambientales@una.ac.cr

May R. H.

Skutch siempre incorporaba reflexiones filosóficas a sus estudios de la naturaleza, buscaba el sentido o el significado existencial de las aves y la naturaleza. Demuestra una concepción de la naturaleza como dinámica, cambiante, sensible y consciente, en la cual las aves y otras manifestaciones de la vida exhiben vida interior o psíquica y libertad (May, 2015). Por tanto, para él la naturaleza está llena de significado.

En su libro filosófico más importante, El ascenso de la vida (Skutch, 2013), argumenta que el universo está regido por el principio de la armonía, e insiste en que la trayectoria de la evolución es, precisamente, a organizar todos los elementos de la existencia en una integrada y armoniosa unidad. Aunque se declaraba ateo, denominaba "divino" este proceso de armonización e integración (Skutch, 2014). Su primer libro filosófico, The quest of the divine (Skutch, 1956), plantea directamente la cuestión de lo divino, mientras que en The golden core of religion (Skutch, 1970) retoma el tema y apunta el propósito de la religión, según sus criterios.

Este compromiso filosófico — en verdad, religioso- enmarcaba sus observaciones de la naturaleza, y fue el fundamento de su compromiso vegetariano; es decir, para él la violencia y la muerte no son permisibles en un universo armonioso. Nunca estuvo dispuesto a mantener un ave enjaulada, y mucho menos a matarla para estudiarla, ni tampoco colaborar en el anillamiento de ellas, porque no quería provocarles "terror mental". Sus investigaciones ornitológicas y otras privilegiaron la convivencia no-competitiva, como la cooperación y la no violencia. De alguna manera, Skutch deseaba que la ciencia fundamentara empíricamente su filosofía.

Este compromiso moral le llevó a rechazar la depredación, que él veía como un error de la evolución. Aunque pacifista, no sentía contradicción alguna al matar depredadores amenazantes para las aves, como serpientes y rapaces. Se justificaba argumentando que lo hacía para proteger a criaturas indefensas, como las aves, y siempre intentó librar de depredadores su finca.

Hacia el final de su vida, en su libro Harmony and conflict in the living world (Skutch, 2000) amplía esta idea - que había planteado en ocasiones anteriores - y abogaba para la gradual eliminación de depredadores y el establecimiento de áreas protegidas organizadas mediante la armonía y la paz. Esto lo llama "biocompatibilidad", incluso argumentaba que la biodiversidad es excesiva y, por tanto, es la causa de la competencia y la violencia; quería "corregir" la naturaleza.

No se duda de que Skutch amaba la naturaleza, pero, de alguna manera, no amaba la naturaleza tal y como es, sino como él quisiera que fuera. Asimismo, cometió un error filosófico, al confundir categorías. Es decir, quiso imponer a la naturaleza la moralidad humana; no pudo aceptar que la naturaleza no tiene moral, por lo menos en el sentido humano.

\section{Importancia para la conservación}

Para Skutch, el medio ambiente natural demuestra importantes lecciones para el vivir diario. Aprender estas lecciones requiere "conocer" a fondo el ave u otra manifestación de la vida. Por tanto, era necesario pasar horas y horas observando sus actividades y, además, pensando, reflexionando sobre el verdadero sentido de lo observado.

\begin{tabular}{|c|c|c|c|c|c|}
\hline 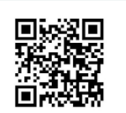 & (c) (1) (5) () & $\underbrace{}_{\text {AMEIENTIISS }}$ & $\frac{O \%}{2)}$ & $\frac{\text { UNA }}{\frac{\text { UNIVERSIDAD }}{\text { NACIONAL }}}$ & 323 \\
\hline
\end{tabular}




\section{Revista de CIENCIAS AMBIENTALES Tropical Journal of Environmental Sciences}

Revista de Ciencias Ambientales (Trop J Environ Sci) e-ISSN: 2215-3896

(Enero-Junio, 2021) . Vol 55(1): 317-326 DOI: https://doi.org/10.15359/rca.55-1.15

Open Access: www.revistas.una.ac.cr/ambientales e-mail: revista.ambientales@una.ac.cr

May R. H.

Así que, "conocer" el bosque, los animales y especialmente las aves, es una clave que caracterizó sus intereses y sus preocupaciones. Significó, para él, la capacidad de penetrar lo evidente y superficial, para descubrir el secreto interior donde reside lo que es verdaderamente real. Para él, el bosque jamás es solo bosque, un animal no es solo un animal y un ave no es únicamente un pájaro. Siempre son algo más, profundo, no evidente a primera vista. En este sentido, para Skutch la naturaleza, y en especial las aves, son sujeto, y no mero objeto para ser investigado o usado solo para fines utilitarios (May, 2013).

Estaba convencido de que las aves tienen subjetividad, intereses propios y capacidad para tomar decisiones. Esto, entendía bien, no es fácil e incluso quizás imposible de saber con certeza. No obstante, creía que la incapacidad de comprobar la subjetividad de las aves no representa en sí un argumento en contra. Más bien, insistía, que mediante la observación y la experiencia directa se puede entablar una relación que permita intuir tal subjetividad.

La naturaleza, percibida como sujeto, nos impone obligaciones hacia ella misma. Es decir, no nos permite explotarla indebidamente y nos obliga a conservarla. Implica ampliar nuestra comunidad moral - nuestro círculo de amigos y amigas - , para incluir a las aves y la naturaleza. Esto significa que nuestra relación moral no está limitada a nuestros semejantes, sino que se extiende hacia las demás criaturas vivientes, incluyendo los bosques y las montañas.

Reclama esto porque creía que todo el orden natural es, en verdad, vivo, y que todas las criaturas, incluyendo los seres humanos, de alguna manera están emparentadas. Nos señala, entonces, la importancia fundamental de una actitud de aprecio y agradecimiento. Por esta razón, según él, la observación y el estudio de las aves es más que un pasatiempo o ciencia, es una vocación moral. Es la certeza de que mediante el disfrute y el estudio de las aves se contribuye al incremento del valor del universo.

\section{Conclusión}

En síntesis, para Skutch, tanto la vida diaria como la investigación científica deben realizarse dentro de un marco de valores que, además, debe guiar la interpretación de los resultados o juzgar la vida cotidiana. En este sentido, enseña que el conocimiento es más que la obtención de datos empíricos, pues siempre hay algo más allá de lo observado o demostrado en un laboratorio. Es decir, poder "conocer" la naturaleza, poder ver o vivir "algo más" es, sin duda alguna, imprescindible para la conservación y la vida sostenible de todas las criaturas vivientes, sean humanas o no.

\section{6. Ética y conflicto de intereses}

El autor declara que ha cumplido totalmente todos los requisitos éticos y legales pertinentes, tanto durante el estudio como en la producción del manuscrito; que no hay conflicto de interés de ningún tipo; que todas las fuentes financieras se mencionan completa y claramente en la sección de agradecimientos, y que está totalmente de acuerdo con la versión final editada del artículo.

\begin{tabular}{|c|c|c|c|c|c|}
\hline 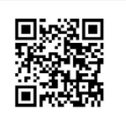 & (c) (1) (9) & 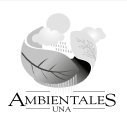 & $\frac{10 \%}{20}$ & $\frac{\text { UNA }}{\frac{\text { UNIVERSIDAD }}{\text { NACIONAL }}}$ & 324 \\
\hline
\end{tabular}




\section{Revista de CIENCIAS AMBIENTALES Tropical Journal of Environmental Sciences}

Revista de Ciencias Ambientales (Trop J Environ Sci) e-ISSN: 2215-3896 (Enero-Junio, 2021) . Vol 55(1): 317-326 DOI: https://doi.org/10.15359/rca.55-1.15

Open Access: www.revistas.una.ac.cr/ambientales e-mail: revista.ambientales@una.ac.cr

\section{Agradecimientos}

A Fabián Cambronero Mena y Lorena Villalobos, funcionarios del Centro Científico Tropical, quienes facilitaron las imágenes de Skutch, de su firma y de su finca; fueron tomadas por César Ruiz, Fabián Cambronero y la empresa de diseño gráfico Moove, respectivamente.

\section{Referencias}

Abarca, C. L. (2004). Alexander Skutch: La voz de la naturaleza. Santo Domingo de Heredia: INBio y CCT.

Comunicación (2005). Alexander Skutch. Revista Comunicación 14, Edición Especial.

Hilje, L, W. Jiménez, y E. Vargas (2002). Los viejos y los árboles. San José y Santo Domingo de Heredia: Editorial Universidad de Costa Rica e Instituto Nacional de Biodiversidad.

May, R. H. (2013). Alexander Skutch: pensador de la vida. Zeledonia 17 (1):1-21.

. (2015). Ornitología filosófica: Skutch y Hartshorne sobre por qué cantan las aves. Zeledonia 19 (2): 64-81.

Skutch, A. F. (1954). Life Histories of Central American Birds. Ilus. D.R. Eckelberry. Pacific Coast Avifauna 31. Berkeley, California: Cooper Ornithological Society.

(1956). The Quest of the Divine: An Inquiry into the Source and Goal of Morality and Religion. Boston: Meador Publishing Company.

(1960). Life Histories of Central American Birds II. Ilus. D.R. Eckelberry. Pacific Coast Avifauna 34. Berkeley, California: Cooper Ornithological Society.

. (1969). Life Histories of Central American Birds III. Fotografías del autor y dibujos de D.

R. Eckelberry. Pacific Coast Avifauna 35. Berkeley, California: Cooper Ornithological Society. (1970). The Golden Core of Religion. London: George Allen and Unwin Ltd.

. (1992 [1979]). The Imperative Call. A Naturalist's Quest in Temperate and Tropical Ame-

rica. Gainesville: University of Florida Press.

(2000). Harmony and Conflict in the Living World. Norman: University of Oklahoma Press.

y CCT.

(2001[inglés 1971]). Un naturalista en Costa Rica. Santo Domingo de Heredia: INBio

. (2013 [inglés 1984]. El ascenso de la vida, segunda edición, revisada y corregida. Trad.

R. Elvir. San José y Cartago: Editorial Costa Rica y Editorial Tecnológica de Costa Rica.






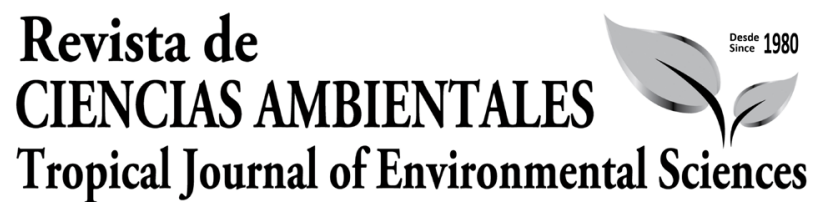

Revista de Ciencias Ambientales (Trop J Environ Sci) e-ISSN: 2215-3896 (Enero-Junio, 2021). Vol 55(1): 317-326 DOI: https://doi.org/10.15359/rca.55-1.15 Open Access: www.revistas.una.ac.cr/ambientales e-mail: revista.ambientales@una.ac.cr

May R. H.

. (2014 [1977]. Aves de Costa Rica. Edición revisada y corregida. San José y Cartago: Editorial Costa Rica y Editorial Tecnológica de Costa Rica.

(2014). Armonización. Aportes filosóficos para la biología y la ética ambiental. Una antología. Ed. R H May. San José: AOCR.

. (2017 [inglés 1985]). La finca de un naturalista. Trad. R. Elvir. San José y Cartago: Editorial Costa Rica y Editorial Tecnológica de Costa Rica.

Stiles, F. G. y A. F. Skutch. (1995 [inglés 1989]. Guía de un naturalista en Costa Rica. Santo Domingo de Heredia: INBio. 